\title{
Accounting Framework to Measure the Environmental Costs and Disclosed in Industrials Companies - Case Study of Societe Cement Hamma Bouziane (SCHB) in Constantine
}

\author{
Hanane Saidi Sief \\ University of Constantine 2, Constantine, Algeria
}

\begin{abstract}
Accounting, being an integrated information system, is not merely influenced by its environment, but also affects environment as well, due to its crucial role in generating the necessary information to decision-makers. It has two main pillars: measuring and declaring the costs that result from the activities of companies, especially industrial companies because they affect the environment. Therefore, the objective of this research is to investigate how well industrial companies are committed to measuring their environmental duties and declaring them in their balance sheets. This topic will be developed over two parts: scientific basis of environmental costs and accounting; environmental measuring and disclosure.
\end{abstract}

Keywords: environmental costs, environmental accounting, environmental measuring and disclosure

\section{Introduction}

The interaction with the environment in its various facets requires the contribution of different arenas from miscellaneous fields and scientific specialties - that is because the environmental studies often depend on the new fruitful results arrived at in such fields - this could patiently show the importance of the environment in tracing and evaluating the direction of scientific and technological developements, taking into account that the environment is the main source of the resources used by the industrial institutions in their productive processes.

There are those who believe that the industrializing and developing processes have greatly, but negatively, contributed to environment pollution - that is due to the negligence of environment-proper considerations when planning out the industrial process. As a consequence, it caused the prodigal loss of primary resources as well as energy. In addition, it ensued from the so-called ambitions plans with regard to realizing the fast growth, together with the excess in intensity of the competition among the institutions functioning in similar sectors. The latter resulted in negative effects on the environment. The accountants encounter difficulty in measuring the charges ensued from these monetarily. The industrial institutions are held responsible for that, because they know the environmental costs.

Hanane Saidi Sief, Master on management sciences, faculty of economics, commerce and management sciences, University Constantine 2, Constantine, Algeria.

Correspondence concerning this article should be addressed to Hanane Saidi Sief, No.1 Building 29, Ain El Bey, City of Ahmed Bouamama, Constantine, Algeria. Phone number: 2130791168559. E-mail: saidi.sief_hanane@ hotmail.com. 
As a result of all that, it is mandatory that all the various institutions, particularly those functioning in environment sensitive industries, take into account all the environmental consideration, when evaluating the environmental revenue. This would require them to develop a professional method in measuring, so as to seriously care about the environment - proper matters which the accountancy possesses within its branches, a side relating to the environment and its issues. Therefore all that is executed within the framework of environmental costs account. Accounting aims at availing future effective information for decision-takers and the environmental policies-makers, and this would purposefully indicate all the environmental social costs of all the processes and activities targeting the protection of the environment from the direct and the indirect disadvantages. In doing so, they depend on two firm bases: measurement and the accounting disclosure about the environmental performance.

\section{Problems}

The problems are summed up in the attempt to know the extent to which the industrial institutions reached in the accounting measurement, their environmental effects, and their disclosure about them. It becomes a necessity especially for its big monetary costs and also the obligations owing to the pollution they cause in the environment. So, the problems can be imbued in the following main query: To what extent do the industrial institutions pursue their obligation in measuring their environmental costs and disclosure those in their financial lists?

\section{Significance of Research}

The significance of this study springs from the excessive interest in holding the social and environmental responsibility. So, the social revenue is taking precedence over its monetary revenue. In addition, the efficiency of the accounting system is measured by the availability of a secondary system which would give information about the environmental performance of the institutions and its effects on society. The study is also important to all institutions of different plans and inclinations so as to actualize the social and environmental dimensions in future plan. That would help them realize their aims and help society in the continual development. Also, they will guarantee their continuity and possibility of evaluating the performance objectively and comparing them to those of other institutions. Moreover, they would put on a competitive feature as the information concerning the environmental performance is of a quantitative and monetary nature. Thus, that makes them affect, in a direct way, the monetary centre of the institution and the result of their activity.

\section{Objectives of the Research}

This research aims to specify the state of the accounting measurement and disclosure about the environmental charges in those industrial institutions. The latter can be done through realizing the following offshoot aims:

- clarifying the nature of environmental costs and the ways of their measuring and the requirements of their disclosure;

- tackling the environmental accountancy basics;

- analyzing the causes of the constrainment of the accounting measurement by industrial institutions' environmental performance and their disclosure about it, and the most important hindrances that impede them to do that.

\section{Research Methodology}

The study of the topic "Accounting framework to measure the environmental costs and disclosed in 
industrial enterprises" in alterations and the attempt to link all these alterations should lead to utilize two approaches: the analytical descriptive method, which is used in the theoretical part of this study because of its dependence on describing the Phenomenon under study and summing up the most crucial results that can be arrived at; a case study within the practical part.

\section{Scientific Basis of Environmental Costs and Accounting}

\section{Environmental Costs-Definition and Classification}

Environmental costs - Definition. That the business sector industrial enterprises include environmental considerations constantly working to improve the environmental performance in the long-term strategy for the environment and ensure the survival of the institutions in the market has been realized.

Accountants are faced with the problem of measuring the costs of pollution forms of cash, which is expressed in environmental costs (Al Doussari, 2007, p. 18).

Expenditures incurred to prevent, contain, or remove environmental contamination. Such costs are generally expensed. However, only in the following cases, the company may elect to either expense or defer the costs: (1) the expenditures either extend the life or capacity of the asset or increase the property's safety; (2) the expenditures are made to get the property ready for sale; and (3) the expenditures prevent or lessen environmental contamination that may result from future activities of property owned (Retrieved from http://www.answers.com/topic/environmental-costs)

According to USA Environmental Protection Agency, the definition of environmental cost depends on utilization of information in a company and the environmental costs can include conventional costs (raw materials and energy costs with the environmental relevance), potentially hidden costs (costs which are captured by accounting system but then lose their identity in overheads), contingent costs (costs in a future time - contingent liabilities), and image and relationship costs (Betianu, 2013, p. 125)

Classification of environmental costs. The novelty of this type of costs differed researchers in the classification and a review of these views can divide environmental costs into the following (Al Sharairi \& Al Awawdeh, 2011, p. 80).

The division for sustainable development of the United Nations has proposed a definition of environmental costs that distinguishes four types of costs:

- The first one is related to all the efforts made by organizations to reduce the environmental effects of their activities, by using "end-of-pipe" measures and technologies;

- The second one is related to all activities made by organizations to prevent their environmental effects before the end of the production process, for example, by using cleaner technologies or by establishing environmental management systems;

- The third and fourth types of cost are defined on the idea that anything that does not enter the product produced by a company is a non-product output, such as wastes, waste water, or lost energy, and that all costs associated to this non-product output are regarded as environmental costs. These include both the purchasing value of the materials and the production costs of producing the non-product output.

The guidance document of International Federation of Accountants (IFAC) on Environmental Management Accounting (EMA) draws that distinction between "waste and emission control costs" and "prevention and other environmental management costs", which, together with research and development projects, helps to reduce the material costs of non-product output and thus increases co-efficiency. 
The environmental cost categories stated by United Nations are as follows.

- Waste and emission treatment includes: depreciation for related equipment; maintenance and operating materials and services; related personnel; fees, taxes, charges; fines and penalties; insurance for environmental liabilities; and provisions for cleanup costs, remediation;

- Prevention and environmental management includes: external services for environmental management; personnel for general environmental management activities; research and development; extra expenditure for cleaner technologies; and other environmental management costs;

- Material purchase value of non-product output includes: raw materials; packaging; auxiliary materials; operating materials; energy; and water;

- Processing costs of non-product output includes: labor costs and energy cost.

The IFAC environmental cost categories are as follows.

- Materials cost of product outputs includes the purchase costs of natural resources such as water and other materials that are converted into products, by products, and packaging;

- Materials cost of non-product outputs includes the purchase (and sometimes processing) cost of energy, water and other materials that become non-product output (i.e., waste and emissions);

- Waste and emission control cost includes: cost for handling, treatment and disposal of waste and emissions; remediation and compensation cost elated to environmental damage; and any control related regulatory compliance cost;

- Prevention and other environmental management cost includes the cost of preventive environmental management activities such as cleaner production projects; cost for other environmental management activities such as environmental planning and systems, environmental measurement, environmental communication, and any other relevant activities;

- Research and development cost includes the cost for research and development projects related to environmental issues;

- Less tangible cost includes both internal and external costs related to less tangible issues. Examples include liability, future regulations, productivity, company image, stakeholder relations, and externalities.

Also, the cost related to environment can be described as cost within internal management account, or external financial accounts.

In this approach, internal environmental cost to the firm is composed of direct cost, indirect cost, and contingent cost. These typically include such things as remediation or restoration cost, waste management cost, or other compliance and environmental management cost. Internal cost can usually be estimated and allocated using the standard costing models that are available to the firm.

Direct cost can be traced to a particular product, site, and type of pollution or pollution prevention program (e.g., waste management or remediation costs at a particular site). Indirect cost, such as environmental training, research and development, record keeping and reporting, is allocated to cost centers such as products and departments or activities.

External cost is the cost of environmental damage external to the firm. These cost can be "monetized" (i.e., their monetary equivalent values can be assessed) by economic methods that determine the maximum amount that people would be willing to pay to avoid the damage, or the minimum amount of compensation, that they would accept to incur it (Betianu, 2013, pp. 125-126). 


\section{Objectives of the Environmental Cost}

Environmental cost of several targets can be displayed as follows (El Fadal, Nour, \& Aldogdji, 2002, p. 227).

- It enables the environmental cost of institutions to study the negative impact of operational processes on the environment and related programs for the protection and budget for these programs, and their impact on profitability and the discovery of new ways to reduce the negative environmental impacts;

- The inclusion of environmental cost in the annual reports contributes to the competent organs of the state to assist in the preparation;

- Long-term plans for natural resources and environmental indicators reports of the various regions and the state needed to achieve the control over the elements of the pollution of the environment;

- Better management of environmental cost must be reviewed periodically to reveal shortcomings in the accounting software used and enable organizations to measure revenue and environmental benefits;

-When investing in shares of companies, environmental information makes supply decision-makers invest in areas with high efficiency in the fight against pollution and avoid not taking into account the cost of environmental pollution in the preparation of its financial statements;

- Disclosure of the environmental costs of the institutions provides information on the nature of the activity, environmental legislation and discretionary capital expenditures and the actual implications for compliance with those regulations, and the associated cost, and their impact on the financial position, liquidity and equity returns.

\section{Concept of Environmental Cost Accounting}

Several developments have been got in various fields. The industrial sector was a part of them, as one of the sectors most closely to the environment and its issues. The industrial enterprises have faced many of these issues to develop their practices in maintain the ecological balance. So they have adopted integrated economic accounting that alternates the traditional ones in the context of environmental cost accounting (Roger, 2004, p. 13).

Environmental accounting is generally perceived as accounting for cost, related to the environment (Reyes, 2002, p. 3).

Environmental accounting means different things "defined": identification, appropriation, and application of environmental cost (Mike, 2013, p. 2).

EMA, for internal use, is as following:

- Cost control and management;

- Correlate business and environmental performance;

- Proper resource management;

- Prioritization tool.

Financial, for external release:

- Governed by G.A.A.P.;

- Financial reports to stakeholder, lenders, etc.;

- Frequently, reporting liabilities financially relevant cost.

Environmental Full Cost Accounting (EFCA) generally refers to the process of collecting and presenting information-about environmental, social, and economic costs and benefits/advantages (collectively known as the "triple bottom line") - for each proposed alternative when a decision is necessary. It is a conventional method of cost accounting that traces direct cost and allocates indirect cost. (Schaltegger \& Burritt, 2000, p. 111) 


\section{Importance of Environmental Accounting}

The environmental accounting is very important for the following reasons:

- It can integrate business and environmental planning;

- It can identify company priorities;

- It can improve product and process design (LCA);

- It can give more accurate cost-benefit evaluations;

- It can be an important step in pollution prevention activities;

- It can support budget planning and resource management (Mike, 2013, p. 3);

- There are demands for environmental excellence from various sectors;

- Traditional accounting systems are primarily geared towards external reporting and disclosures;

- Accurate information on environmental cost is a key tool for internal business decisions (Reyes, 2002, p. 7).

\section{Accounting Treatment of the Environmental Effects}

The environmental accounting is an active service, being developed to promote initiatives and environmental policies by including cost and environmental benefits that result from the practice of institutions for their activities, not limited importance to governments and environmental protection agencies without the other, and the need for a framework for environmental accounting in economic institutions to achieve the advantages of the accountant and the decision maker.

The institutions, especially industrial ones, in their attempts to reduce the effects of pollution and control, as well as for processing and removal of its effects on the environment and society, have practiced many activities; and whether it is voluntary or mandatory, they bear the cost of the promotion of those activities and adhere to it that can result in income and benefits. As the accounting through information system deals with the events and processes as well as the conditions resulting from the sum of the activities on contact economic institutions, method is to be set by which to determine the environmental cost and to trace through the accounting information systems in organizations, and in this area some studies have shown that there are four ways to identify environmental cost and traced, namely (Dhahabi \& Mouwafak, 2009, pp. 10-11):

- Air traditional accounting system;

- The use of cost accounting faculty;

- The use of system cost on the basis of activities (ABC) to link the activities related to the environment with the cost incurred because of it;

- The use of estimating total cost, especially in investment decisions.

The success of the process of assessing the environmental impact requires the adoption of integrated economic accounting instead of the traditional ones. This new kind of accounting can be considered as a method to assess the environmental and social impact of the economic projects. So the method aims to provide actual and future information to decision-makers and environmental policy-makers. Beside the purpose behind providing information is the identifying of all the environmental and social cost related to activities done by industrial companies to protect the environment from direct and indirect damages.

\section{Measurement and Disclosure of Accounting for Environmental Performance}

There is no doubt that users of financial reporting need the environmental information to make decisions. This environmental information is mainly the amount of costs and benefits that return to the society and 
stakeholders. All of this cannot be done without following the process of environmental accounting measurement and disclosure.

\section{Accounting Measurement for Environmental Performance}

Researchers presented in the areas of different measurements and multiple definitions for the measurement process are even different somewhat in shape, but they are consistent in content as follows:

(1) Accounting measurement is only an expression of quantitative and critical phenomenon events and facts of certain financial and economic unity, and displayed in the useful and clear form (Ahmed, 2009, p. 154).

(2) The accounting measurement of environmental processes can be defined as: It is to determine the values of all elements of the costs generated by the commitment of industrial enterprises, social and environmental responsibilities, whether this commitment sole discretion is under the law (Chhadha, 2010, p. 283).

Accounting measurement of assets and liabilities environmental. The objective of the accounting measure of environmental assets and liabilities is to seek the fundamentals of measuring the environmental positive and negative contribution.

Accounting measurement of environmental assets. The accounting measurement of environmental assets is reflecting environmental expenditures which permitted them to benefit more than one accounting period. Also obstacles imposed on polluters to reduce their waste increase costs placed on them, which is designed to measure the costs of treatment:

- provide cost information that will help determine how much cost is borne by the institution to address the pollution damage resulting from the activity;

- link the level of treatment required to achieve approval with cost;

- determine the impact of treatment cost on cost prices in industrial enterprises.

There are many difficulties, however, to achieve the objectives of measuring the costs, including the difficulty of obtaining information on the cost of the damage, pollution treatment costs borne by individuals, and these difficulties are due to the lack of great interest to the problem of pollution treatment, as well as the weakness of environmental awareness.

Due to the difficulties in increasing the personal judgment of the evaluation of accounting for the effects of environmental processes on the origins of the assets and liabilities of industrial enterprises and the absence of accounting standards to evaluate and measure such impacts, it affects processes generally on the assets and liabilities of institutions.

The most prominent effects on the environmental assets include as follows (Bouhafs, 2007, p. 120):

(1) accounting measurement of technological systems aiming at addressing environmental pollution emitted at the end of the production line;

(2) evaluation of the reduction in fixed assets or inventory because of the environmental impacts, resulting from damaged or obsolete inventory environmentally, the shortage of fixed assets due to environmental accidents.

Accounting measurement of environmental liabilities. Environmental obligations are known as the amount of money paid by industrial companies in the future to repair the environmental damage caused by their activities affecting the environment.

Problems of measurement and evaluation of environmental accounting. Accounting measurement of 
environmental processes did not meet the attention given by those operations to the kind of measurement, due to the unavailability of cost prices and market prices that could conduct the evaluation financial accounting for such operations. Also damage to the environment raises several questions related to the special difficulties accounting for the costs of the environmental performance of industrial enterprises, which comes in the forefront of the following:

- the difficulty of determining the causal relationship between the offending act and the damage it caused;

- the difficulty of determining an effective pollution once and for all;

- the difficulty of limiting damage to the environment;

- diversity in the forms of environmental corruption;

- absence of an accounting standard which can be recognized by an independent accounting treatment of ongoing environmental expenses, especially those for initiating them any cash yield.

\section{Disclosure of Accounting for Environmental Performance}

Concept of environmental disclosure. Disclosure in its comprehensive sense means the disclosure of confidential information and its authorization, as it reflects well on the detection revealing accounting.

It is the commitment to publish all the facts and information related with the activity of industrial companies which will influence the decisions of the investor.

The environmental disclosure is the method or the way in which companies can inform the community with its different limbs, from the various activities related with the environment, according to the financial statements or reports, as this is latter an appropriate tool to achieve this objective.

The United States and Britain are also of the most interest by subjecting environmental performance of the institution to accounting disclosure, where they show their interest in professional organizations specializing in the two countries, as well as the Commission Securities who needs to disclose the environmental impact in terms of cost and yield, as recommended by the committee on accounting standards, such as England which needs to disclosure environmental information and report on the disclosure of institutions for the cost and benefits resulting from those activities .

In Australia and New Zealand, some studies have shown that there are a few institutions which have attempted to disclose their activities in the area of environmental disclosure (Tahar, 2011, pp. 447-450).

Motives and mechanisms for disclosure of environmental information. With increased needs of users of financial statements to the disclosure of information environmental and to deal with inadequacies of traditional disclosure, there was an urgent need to develop an accounting standard to include considerations of environmental disclosure.

The accounting disclosure in its current form does not meet the needs of information and data on the social responsibility of the institution to the protection of the environment, and then there was an urgent need to develop a standard disclosure in accounting thought to include environmental disclosure in the form of supplements lists and traditional reporting, or in the form of lists and independent reports, leading to increased efficiency of the operation of information by decision makers, and then rationalized their decisions relating to the assessment of financial assets and economic performance, taking into account environmental and economic responsibility of the institution.

The voluntary environmental disclosures based on a number of factors are summarized as following (Ben Bouzian \& Ben Dhab, 2012, p. 273): 
(1) working on building better relations between the institution and stakeholders, such as government agencies and inter stock and employees of the institution and the customers and suppliers and financiers and pressure groups, and the use of disclosure as a way to inform the community as a whole that the institution is voluntary disclosure of environmental information;

(2) trying to improve the image of the institution within the community which is engaged by the activity, especially for organizations that have been heard for the damage caused by the occurrence of accidents or environmental disasters, which supports the trust and respect of society and individuals in institutions, thereby increasing demand for its products and the expansion of its investments, which is reflected in its impact on the end result of its activity and its money, and the value of it;

(3) getting ready for the application of environmental laws and regulations that will require the disclosure of environmental information and are expected to be binding on all institutions;

(4) using the disclosure as a means to reach a competitive position in the field of advanced enterprise activity and the preservation of its current location;

(5) getting the tax treatment distinctive in terms of the exemption or reduction of taxes imposed on it, and the United States is one of the first countries interested in encouraging institutions to protect the environment;

(6) reducing the cost of production because of material support, low-cost funding, or distinctive tax treatment leading to increase the size of the institution's activities. Preassigned institution uses its resources as efficiently as possible and at the same time protects the environment from the harmful effects of pollution to help them increase profits;

(7) disclosure of environmental expenditures separately in the financial statements will allow measurement of the utility, such as helping investors to see clearly the policies adopted by the institution for the protection of the environment, and then rationalize their decisions concerning the institution.

\section{Conclusions}

This research, with its practical and theoretical sides, has ended with theoretical results: Pollution is one of the important environmental impacts which require a big part of research to control other factors of environmental impacts.

The business sector has realized that institutions, especially those active in industries sensitive to the environment must include continuous environmental aspects that improve the environmental performance of the environmental strategy of long-term. This is to ensure the survival of industrial enterprises in the market. The resulting costs of this are included in what is known about the environmental costs.

This latter is treated with a related accountancy framework and it is considered as one of the social accountancy components that aim at protecting renewable environmental and the nonrenewable sources from exhaustion and deterioration because of its being a complementary system for information in an exchangeable relationship with the environment. The effective role plays in decision-taking is realized via the availability of the accounting information relating to the environmental activities performed by the industrial institutions within their financial reporting, as it is considered as the main helpful tool in planning and decision-making and drawing the targeting policies of protection against the environmental effects. Accountancy is then able to effectively exercise its efficient role by depending on two main bases (pillars): measurement and the accounting disclosure.

The end from this study is to make an attempt to know the extent to which the industrial institutions are 
committed to measuring their environmental effects and their disclosure about environmental effects through a practice in the industry of cement Hamma Bouziane (SCHB) Constantine, an industry of a negative effect on the environment.

This methodological framework helps to identify such cost in other industries, as an invitation (a call) for the economists to point at the importance of the environment in the process of evaluating the performance and the revenue (results). Here are some conclusions and recommendations:

- There is a constrainment in the process of accounting measurement and their environmental effects and their disclosure about environmental effects in their financial reporting, and that the environmental disclosure takes from taxes and fines that the institution pays via constant values the investments acquired to protect the environment;

- There are a lot of impediments that constrain the institution in accounting revealing its environmental performance, and the most prominent impediment is the paucity in educational programs of defining the requirements of revealing the environmental performance;

- The lack of mandatory rules reveals the environmental performance and the difficulties in measuring the environmental cost;

- There is a lack of harmony between the accountant systems followed by the institution and the new discoveries in the new social and economical environment, in particular, the inefficiency of this system in analyzing the components of the environmental performance costs;

- This research could not get all the information about the cost components in the factory, and what each section takes from counting due to the lack of a developed analytical accountancy;

- As for the results of the cost of treating the industrial pollution, it's clear that the institutions under study exert considerable efforts so as to remove/eliminate dust which contributes to reducing the gap between the disadvantages caused by this pollution and the investment directed to dissolving this problem.

From the conclusions, this research arrives at a group of suggestions, among which the important ones are:

- There should be a necessity of the complementarity between the systematic factors and the accountant policies suitable in the field of analyzing the elements of the environmental performance costs, piling them and their relation with the activity cycle of the institution. The role of the accountant measuring will be shown through the data and the qualitative and quantitative environmental information relating to the environmental cost variables that influence the economic performance of the institution, and their revelation about their role in protecting the environment, and reducing the negative environmental effect of their activities;

- There should be an informational bank that would help avail the information so to measure pollution disadvantages and treat them;

- There should be a suitable taxation system and policy for the social and environmental accountancy;

- There should establish an environmental information system so as to improve managing the environment which is a principal condition of integrating the environmental considerations in different activities.

\section{References}

Ahmed, H. D. (2009). Behavioral entrance in financial accounting. Amman: Safa House Publishing and Distribution.

Al Doussari, A. M. (2007). The importance of accounting environmental costs in improving the quality of accounting information-A field study on industrial companies listed on the Kuwait stock exchange (Master of Accounting, College of Business, University of the Middle East).

Al Sharairi, J. A., \& Al Awawdeh, W. M. (2011). The impact of environmental costs on the competitive advantage of 
pharmaceutical companies in Jordan. Middle Eastern Finance and Economics, 15, 76-91.

Barron's accounting dictionary. (2013). Environmental costs. Retrieved from http://www.answers.com/topic/environmental-costs

Ben Bouzian, M., \& Ben Dhab, A. (2012). The environmental impact of the disclosure on the cost of capital. Proceedings from

The International Scientific Forum on the Behavior of Economic Institutions in Light of the Challenges of Sustainable Development and Social Justice, the University of Cassidy Merbah, Ouargla, Algeria.

Betianu, L. (2013). Environmental cost accounting. Retrieved from $\mathrm{http} / / /$ steconomice.uoradea.ro/anale/volume/2007/v2-finances-accounting-and-banks/26.pdf

Bouhafs, R. (2007). Environmental audit in the economic foundation-A case study of the Algerian Pipe Industries (Master in Economic Sciences, Faculty of Law and Economic Sciences, University of Cassidy Merbah, Ouargla, Algeria).

Chhadha, A. (2010). Accounting measurement of the costs of the environmental performance of the company Syrian general fertilizer and its effect on the ability Altnavcheh in the field of quality. Journal of Damascus University economic, 26(1), 273-304.

Dhahabi, A, \& Mouwafak, A. M. (2009). Accounting measurement of the effects of environmental and disclosure-Applied research in one of the industrial companies, Iraq. Journal of Studies Accounting and Finance, 2(8), 61-93.

El Fadal, M., Nour, A., \& Aldogdji, A. (2002). Contemporary accounting problems. Amman: Dar soft for publication and distribution.

Mike, M. (2013). Environmental cost accounting. Retrieved from http://www.deq.state.mi.us/documents/deq-ead-p2-mbp3-wrkshpfeb02-denso.pdf

Reyes, C. (2002). Environmental management accounting (EMA): A tool for decision makers (Project of Environmental Management Capacity Building for the Philippines, CP\&EMA training Workshop, Astoria Plaza, Pasig City).

Roger, L. B. (2004). Business strategy and the environment. ISI Journal Citation Reports, 13(1), 1-63.

Schaltegger, S., \& Burritt, R. (2000). Contemporary environmental accounting. Sheffield: Greenleaf Publishing.

Tahar, A. H (2011). Accounting disclosure about the environmental performance in the National Cement Company in Libya-A scoping study. Journal of Damascus University Economic, 27, 441-459. 